\title{
STUDY REGARDING THE MOTIVATIONAL DIFFERENCES OF PROFESSIONAL ATHLETES
}

\author{
Professor Radu Ababei \\ PhD., "Vasile Alecsandri" University of Bacău \\ e-mail:raduababei@ub.ro
}

\begin{abstract}
The subject of motivation in sports is a widely debated one in the professional literature, either by psychologists or by coaches, most of the times stopping at the identification of the main markers that favor or hurt top performance.

The purpose variable in relation to the nature and aim of the sport, and to the motivation, where the results were almost identical.of this study is to provide information regarding the reaching of motivational goals by individual and team sports athletes, by highlighting the components that will allow the athletes to face the negative psychological states successfully and to be able to express their peak performance ability.

For this study, a group of 86 male athletes were selected, aged 18-25, divided into two groups, one for individual sports and one for team sports. The hypothesis was that there are not any significant differences between the individual and team sports athletes in regards to motivation.
\end{abstract}

\section{Key words: motivation, sports, performance}

\section{Introduction}

In sports, motivation is important to achieve success. People often say that great performances are based mostly on innate abilities. But in order to reach the highest level in a sport, one must have talent, must work hard to perfect and, not in the least, one must be motivated. Looking at the world of sports, one realizes that the performances of great athletes represent a combination between physical abilities and the burning desire to be the best. Many of them succeed because of a strong inner will, this overcoming what is lacking is physical qualities, such as height, speed, strength, or dexterity.

The subject of motivation in sports is a widely debated one in the professional literature, either by psychologists or by coaches, most of the times stopping at the identification of the main markers that favor or hurt top performance.

Motivation is understood to be "the entirety of the inner motives of the conduct, either innate or acquired, conscious or not, be it either simple physiological needs or abstract ideals" (Roşca, A., $1943^{-}$. Taylor (1994) saw motivation as the basis of a pyramid to success, while Boyce et al., 2001; Van Aken, 1994 have emphasized the "goal orientation", "goal setting", or the "motivational climate".

In regard to the internal or external origin of motivation, Zörgö B states that the actual external factor that starts (or stops) a process_cannot be considered a reason for the phenomenon without a relation to a need, an intention, or an aspiration of the subject".

In professional sports, motivation plays a determining role because it is the basis for sports training and for performing it to the best of everyone's abilities. Motivation in professional sports must be regarded from the point of view of both the athlete, the professional team (coaches, 
physician, psychologist, manager, etc.), and the social entourage (family, friends, etc.) (Nae, I.C., 2010).

One must also make a distinction between "motivation" and "motive", because each of these terms has a specific connotation. While the term "motivation" refers to an energizing state, the term "motive" classifies the energized state and refers to a specific behavioral disposition. For example, Atkinson (1964) stated that: "the term motive is used in regard to a relatively general and stable personality mood that is presumed to be one of the determining factors of motivation, the tendency to look for the path to reach a goal".

Motivation to reach goals cannot be described as something that appears during competition, but as a "permanent trait", formed during the preceding weeks, months, and years. It is an essential element of human personality and directs a person's activity, making it more (or less) dynamic. This characteristic, "the ability to direct one's activity" must be understood as the common function of the motor strength (which is a permanent ability of the personality) and the consequences of what a given individual expects from his actions (Franken, 1993).

Motivation determines people to set realistic, but challenging goals. The top athletes have a great desire to succeed and do not give in to failure. The top performers tend to enjoy challenges, they need feedback and respond well to constructive criticism, they do not fear failure and they abandon the sport only after they have peaked in their career. Often, professional sport training is rigorous, painful, or even harmful. Nevertheless, the athletes with top performances are capable to confront the desire to give up, resulting from a drop in the need to perform and the impression that they are doing something that is banal and easy, even if that performance required a lot of time and effort. In order to move on, these athletes must have something to motivate them to push their limits and to come back from any negative experiences (Kamlesh, 2004).

Psychological training leads to ensuring there is a motivational underlining, its character being more or less optimal. In regard to the relation between motivation and success, it is revealed by the Ekes-Dudley law. Over-motivation and under-motivation can have negative effects, leading to a block or a disinterest from the athlete for the competition (Ababei, R. 2006).

\section{Purpose, hypothesis, and research methods}

The purpose of this study is to provide information regarding the reaching of motivational goals by individual and team sports athletes, by highlighting the components that will allow the athletes to face the negative psychological states successfully and to be able to express their peak performance ability.

The hypothesis of this study was that there is no significant difference in regard to achieving motivation between the individual sports and the team sports athletes.

\section{Research subjects}

This study was conducted on a group of 86 male and female athletes, aged between 18-25 years old, of Bacau county, divided into two groups, one of individual sports athletes and the other of team sports athletes.

Table 1 presents the subjects participating in this experiment. Considering that all the subjects are of legal age, the author got their written consent to take part in the study.

\begin{tabular}{|c|c|c|c|c|}
\hline \multicolumn{4}{|l|}{ Table 1. The research subjects } \\
\hline No. & Individual sport & No. of subjects & Team sport & No. of subjects \\
\hline 1 & Track \& field & 16 & Soccer & 23 \\
\hline 2 & Boxing & 14 & Volleyball & 8 \\
\hline 3 & Wrestling & 13 & Handball & 12 \\
\hline
\end{tabular}




\section{Development of the research}

Bouet (1969) has investigated the reasons why people practice sports in order to get information about the integrative function of sports. Using a questionnaire, he gathered data from 1,364 French male and female athletes practicing various sports. The analysis of the answers to his questionnaire presumed that

1) although the desire to make friends is not a main reason, this contributes considerably to bringing athletes together;

2) the "need for victory" combines itself with a strong affinity for the group, especially in team sports.

This study used Bouet's questionnaire, which is presented below.

\begin{tabular}{|l|l|}
\hline 1. Motor needs & $\begin{array}{l}\text { a) The need to spend energy } \\
\text { b) The need to exercise }\end{array}$ \\
\hline 2. Self-assertion & $\begin{array}{l}\text { a) Aspects of self-assertion } \\
\text { b) Favorable conditions for self-assertion }\end{array}$ \\
\hline 3. Looking for compensation & $\begin{array}{l}\text { a) Complementary and balancing } \\
\text { b) To overcome } \\
\text { c) To substitute }\end{array}$ \\
\hline 4. Social tendencies & $\begin{array}{l}\text { a) The need to join } \\
\text { b) The desire to integrate }\end{array}$ \\
\hline 5. Interest for the competition & $\begin{array}{l}\text { a) The need to succeed } \\
\text { b) The need to compare oneself with the others } \\
\text { c) The need to oppose another person } \\
\text { d) The desire for the unexpected }\end{array}$ \\
\hline e) The pleasure of experiencing the tension of a \\
competition
\end{tabular}

\section{Results of the research}

The interpretation of the data for each of the 11 items was as follows.

In regard to the first item, referring to the motor needs, the results are shown in figure 1. 
Figure 1. Item 1 results

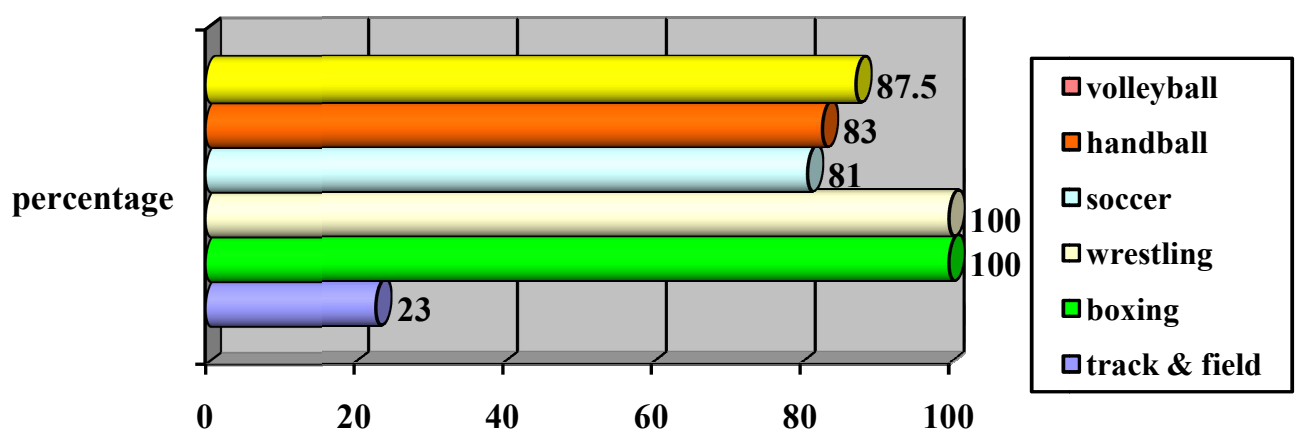

The analysis of the results highlights an overwhelming presence of the tendency to practice sports from a need to spend energy, an exception being the track and field athletes, for whom the need to exercise takes the lead. The figure also highlights that in regard to team sports, one can talk about a quasi-similitude of the results, varying between 81 and $87.5 \%$ of the subjects. Also, in the individual sports of wrestling and boxing, it can be seen that the subjects have chosen the need to spend energy as a reason for practicing that sport.

In regard to self-assertion, all of the 86 subjects have stated that they practice professional sports as an opportunity for self-assertion, believing that sports are the best way to achieve social and professional heights, in accordance with their temperament and aspirations.

In regard to the third item, referring to seeking compensation, the results are shown in figure 2 .

Figure 2. Item 3 results

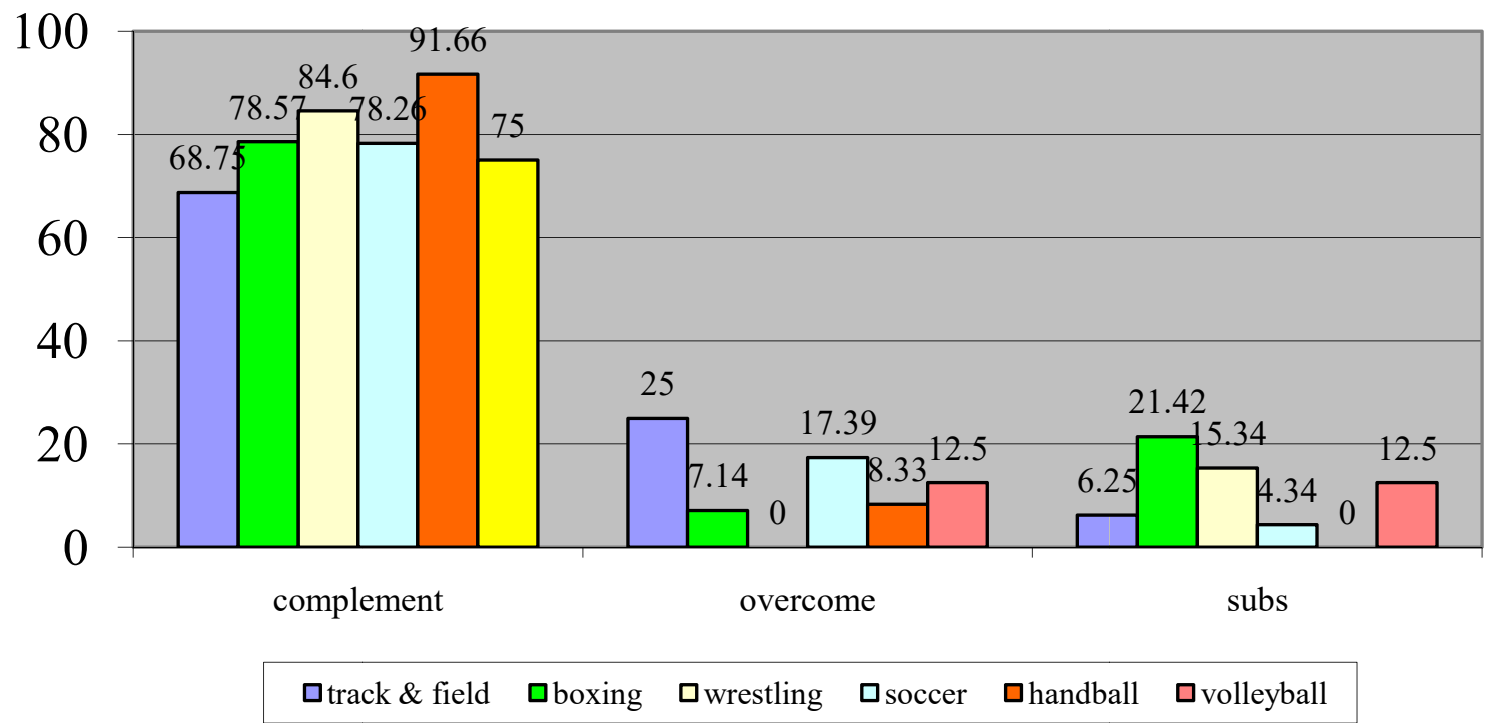

Figure 3 shows that professional sports represent mainly a complementary and balancing activity for the subjects. This answer is preponderant in handball and wrestling, but the other sports as well recorded values of over $75 \%$ for this item. It is interesting to note, however, the high percentage of practicing sports as a substitute, encountered in boxers, who find in professional sports the possibility to substitute the hard conditions in their homes, a significant correlation existing between this item and the financial conditions of the respondents.

One must also notice that there is an important percentage of athletes who practice professional sports to overcome certain demands induced by the social environment - school or a demanding job. Here also there is a significant correlation between the demanding job and the high percentage of practicing sports as means of re-balancing oneself.

In regard to the fourth item, referring to the social tendencies, the results are shown in figure 3. 
Figure 3. Item 4 results

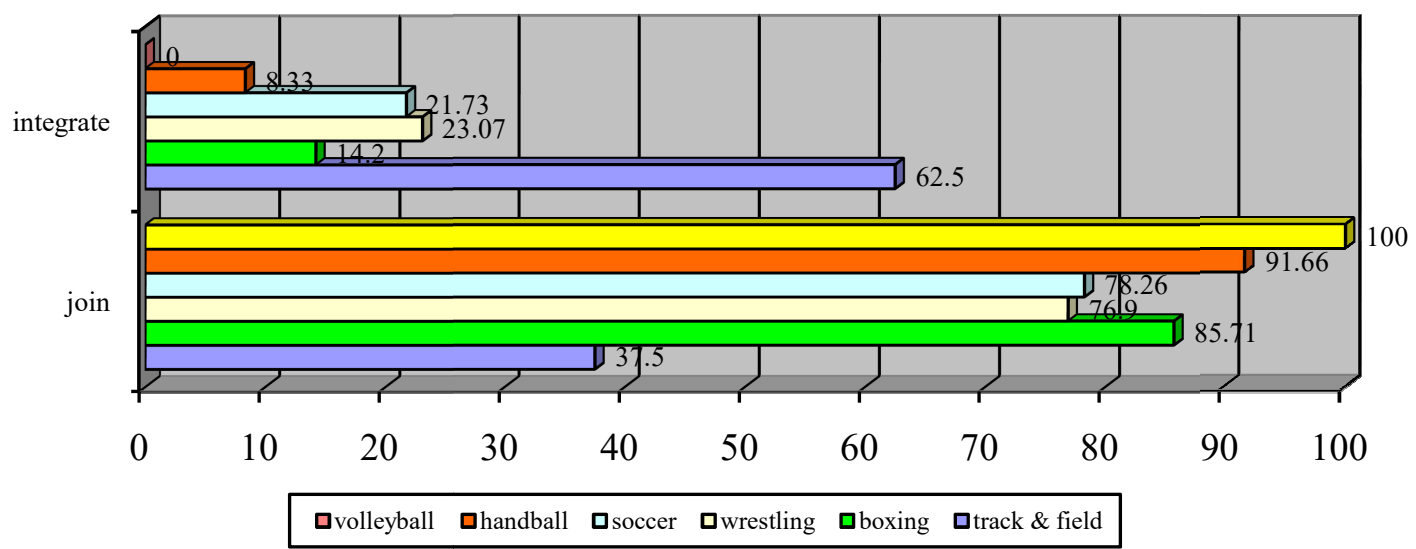

The results show a need to join in over $78 \%$ of the subjects, with the exception of the track and field athletes, who, this time also, recorded a different result than the other five sports. It is interesting to notice that in team sports the need to join has the highest values, handball and volleyball recording over $90 \%$; it is also interesting that the significant percentages recorded by the boxers and wrestlers for their teams are identified with the possibility for self-assertion, creating a feeling of strength and security.

In regard to item 5, the distribution is almost equal for the five answer choices; thus one cannot speak of one reason dominating the rest, but there is a slightly dominant however insignificant, need to succeed.

In regard to item 6 , the desire to win, the dominant answer is the desire to posses, with over $86 \%$, the other $14 \%$ being for patriotism. There is a significant correlation between the performance level and the level of patriotism. The athletes feel themselves more patriotic as their performances have greater value internationally.

Perhaps the most interesting item is number 7 , the one referring to the desire to be a champion.

Figure 4 shows the results:

Figure 4. Item 7 results

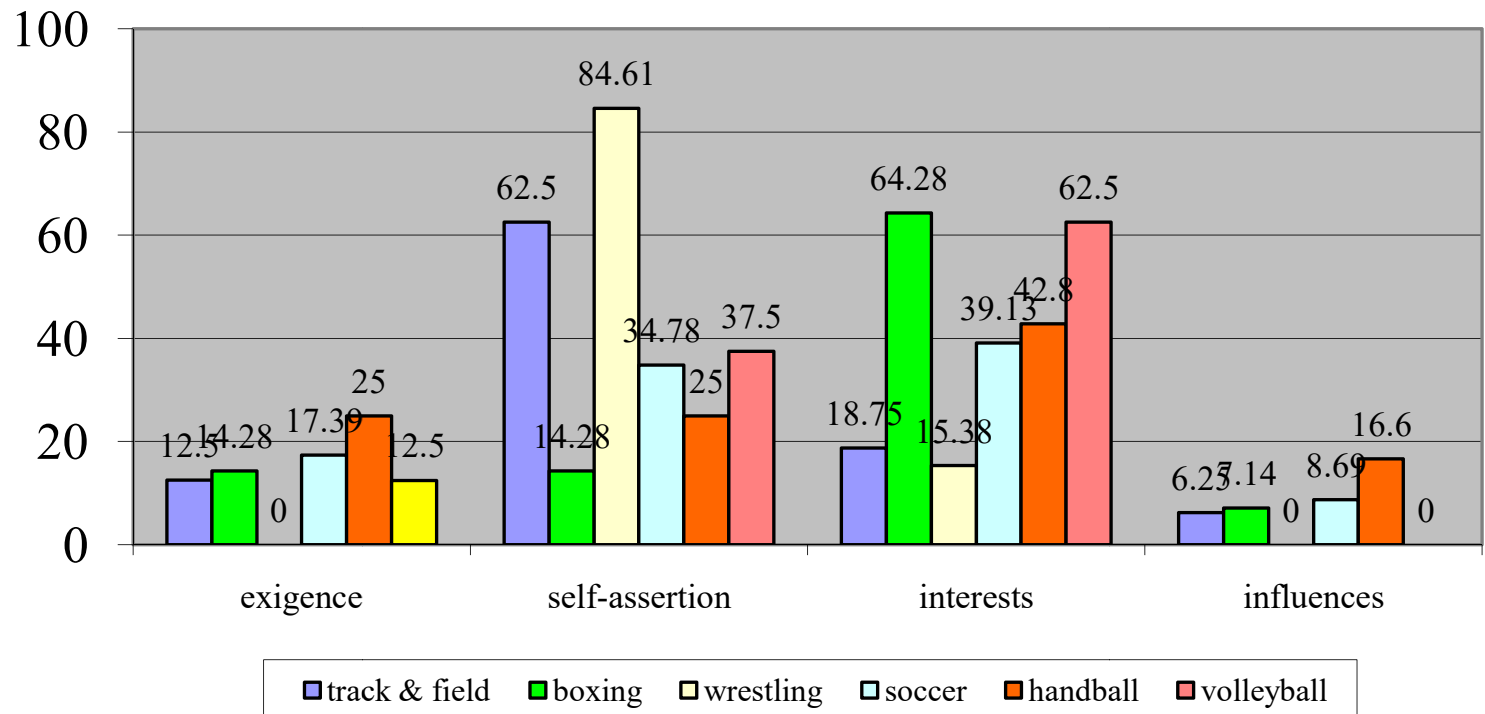

Figure 7 expresses the best the reason why the subjects practice professional sports. One can notice the heterogeneous results, but at the same time that the desire for self-assertion and material interests constitute the main reasons why the young athletes accept the shortcomings 
and the effort, which is taken most of the times, to the upper limits. One must notice also that there are athletes who practice sports at the counsel of third parties, most of the times parents, but also athletes who practice sports because they are exigent with themselves, wanting to prove their value first to themselves and second to others.

Another thing to observe is the important percentage of young boxers for which the sport is a way to gain money, which, however, most of the times ensures only the bare minimum for their families.

The highest percentage for the desire for self-assertion was recorded by wrestlers, for whom the athletic glory is everything, perhaps because their financial gains are not as substantial as in the case of team sports, or boxing, or track and field (which lately has offered the possibility to gain significantly, especially at top levels).

In regard to item 8 , all of the subjects have indicated the fighting spirit as the reason why they practice their sport, and none of them have recognized the aggressive component, not even in the control questions.

It is also interesting that $93.02 \%$ of the respondents did not check anything in item 9 , maybe because most of them perform indoors or on courts that do not offer any special natural environment. This result can be explained also by the fact that at this top performance level, the focus is very high, and there is no time to contemplate nature. The author must remind the reader the case of many great athletes who, although traveling around the world, have seen only the airport and the place of competition.

\section{Conclusions}

In conclusion, motivation represents a basic condition to practice sports, and especially to achieve top performances, determined by internal and external motivational factors. These factors depend on the way in which the basic human needs are lived but also on the way in which the external, social, and pedagogical factors have acted.

The results of the research have proven that there are not significant differences in regard to the reasons or the motives why young people practice professional sports, motivation being a field where one cannot separate between individual and team sports. Many times, the individual sports athletes act as a team, like in track and field relays, or team events in boxing or wrestling, but there is also the case where an entire team can unite to help a single player that can make a difference.

The problems that can lead to the disappearance of motivation are many, starting with an early specialization of an athlete in track and field, which can reduce substantially his or her longevity (Hagimă, M., Ababei, C., 2017) and up to a lack of upper echelons for senior performances, as in the case of soccer and basketball in Bacau county.

\section{References}

1. Ababei R (2006), Teoria şi metodologia antrenamentului sportiv, vol 2 Ed. PIM Iaşi

2. Atkinson J (1964) An Introduction to Motivation, D. Van Nostrand Company, Inc (1965), Oxford, England: Van Nostrand;

3. Boyce AB, Wayda VK, Johnston T, Bunker LK, Eliot J (2001). The effect of three types of goal setting conditions on tennis performance: A field-based study. J. Teach. Phys. Educ., 20

4. Crespo M (2002). Tennis psychology: An overview and update. Newsletter of Society for Tennis Medicine and Science, 5: 12.

5. Franken, R.E. (2007), Human Motivation. (6th Edition).Thomson/Wadsworth, Australia

6. Gould D, Tuffey S, Udry E, Loehr J (1996). Burnout in competitive junior tennis players: II. Qualitative analysis. Sport Psychol., 10

7. Hagimă Maria, Ababei Cătălina (2017), Specializarea timpurie în atletism la ora controverselor, Analele Universităţii Dunărea de Jos din Galaţi, 
8. Kamlesh, M.L., (2004), Athletic Personality: A Psychological Probe, Khel Sahitya Kendra K.S.K. Publishers and Distributors, New Delhi

9. Nae, I., C.( 2010), Aspecte generale privind motivaţia în sportul de performanţă, Rev Marathon,

10. Roşca Al. (1943) Motivele actiunilor umane. Editura Institutului de psihologie al Universitatii. Cluj

11. Rotter JB (1954). Social learning and clinical psychology. Englewood Cliffs, NJ: Prentice Hall.

12. Taylor J (1994). Pre-match routines. International Tennis Federation Coaches Review, 4, 11.

13. Van Aken I (1994). Theory of goal setting. Presentation from European Tennis Association Coaches. Symposium. Helsinki, Finland

14. Zörgö B., (1980) Motivatia în „Problemele fundamentale ale psihologiei”. Sinteze I. Editura Academiei RSR. Bucharest. 